\title{
Normal weight diabetic patients versus obese diabetics: relation of overall and abdominal adiposity to vascular health
}

\author{
Alla Lukich', Dov Gavish ${ }^{1,3}$ and Marina Shargorodsky ${ }^{2,3^{*}}$
}

\begin{abstract}
Objective: The present study investigated the impact of overall obesity defined by BMI and abdominal obesity defined by WC on vascular atherosclerotic changes in obese and normal weight diabetic subjects.

Design and methods: 285 subjects were divided according to presence diabetes mellitus (DM) and obesity: Group 1 included 144 nonobese subjects without DM; Group 2 consisted of 141 type 2 diabetic patients. Then diabetic patients were divided into two groups according to presence of overall obesity, defined by BMI and furthermore, abdominal obesity, defined by waist circumference (WC). Pulse wave velocity (PWV) and augmentation index (Al) were performed using SphygmoCor (version 7.1, AtCor Medical, Sydney, Australia).

Results: Between Group Comparisons by BMI: Diabetic subjects with and without overall obesity did not differ from one another in terms of Al and PWV.

Between Group Comparisons by WC: Al as well as PWV increased consistently from Group 1 to Group 3, Al and PWV were significantly higher in abdominally obese diabetic subjects than in the diabetics without abdominal obesity ( $p$ $=0.008$ and $p=0.013$, respectively). Significant by-group differences in PWV and Al persisted after adjustment for age, sex, blood pressure, fasting glucose and BMI.

Conclusions: Abdominal obesity defined by WC was associated with significantly higher Al and PWV in in both diabetic men and women; whereas overall obesity defined by BMI did not predict adverse vascular changes in this study population. Abdominal obesity was associated with an adverse effect on blood vessels, independently of age, sex, blood pressure, fasting glucose and BMI.
\end{abstract}

\section{Introduction}

In diabetes, arterial stiffening is consistently observed across all age groups and may contribute, in part, to the excess cardiovascular morbidity and mortality observed in these patients [1,2]. Several pre-existing risk factors including hypertension, dyslipidemia and obesity may further increase the cardiovascular risk associated with hyperglycemia, leading to excess CVD risk at an earlier age. Physiopathology that links increased adiposity as well as diabetes to arterial stiffening is not precisely known. One suggested mechanism is through insulin resistance, which commonly accompanies obesity and type

\footnotetext{
*Correspondence: marinas@wolfson.health.gov.l

${ }^{2}$ Departments of Endocrinology, Wolfson Medical Center, POB 5, Holon 58100 , Israel

${ }^{3}$ Sackler Faculty of Medicine, Tel Aviv University, Tel Aviv, Israel

Full list of author information is available at the end of the article
}

2 diabetes mellitus. A reciprocal relationship exists between insulin resistance and endothelial dysfunction, considered to be a key initiating step in the atherosclerotic cascade $[3,4]$. However, not all type 2 diabetic individuals demonstrate similar insulin resistance as well as cardiovascular risk factor profiles. Obese type 2 diabetics have significantly decreased insulin-stimulated glucose disposal and insulin sensitivity index, confirming that insulin resistance is the major contributor to the pathogenesis of hyperglycemia in obese subjects with type 2 DM , whereas lean type 2 diabetics are characterized primarily by a defect in insulin secretion [5,6]. Currently, there is no consistent evidence regarding differences in term of cardiovascular morbidity and mortality between obese and nonobese diabetic patients. Even less information is available regarding vascular impact of different obesity anthropometric indexes such as 
waist circumference (WC) and body mass index (BMI) in obese and normal weight diabetic subjects.

Estimation of arterial stiffness has been reported to be a useful method for assessment of early preclinical atherosclerosis [7]. PWV, which is associated with higher risk of cardiovascular morbidity and mortality and AI, which recently been considered as a valid biomarker, provide valuable information regarding vascular health $[8,9]$.

The present study was designed to investigate the impact of overall obesity defined by BMI and abdominal obesity defined by WC on vascular atherosclerotic changes in obese and normal weight diabetic subjects.

\section{Materials and methods}

\section{Subjects}

The study group consisted of 285 Caucasian subjects, (185 women and 100 men, mean age $61.4+/-10.9$ years) who were recruited from the outpatient metabolic clinic and evaluated for the study. The study participants were divided into two groups according to presence of type 2 diabetes mellitus: 144 nonobese subjects without DM (DM-Ob-) defined as the control group and 141 diabetic subjects. Study participants were classified as diabetic if fasting plasma glucose level was $\geq 126 \mathrm{mg} / \mathrm{dl}$ on at least two blood samples, or if they were treated with antidiabetic medications. Then, diabetic patients were divided into two groups by presence of overall obesity, according to BMI: Group 2 consisted of 62 diabetic non obese subjects (DM + Ob-) and Group 3 contained 79 participants with diabetes and obesity $(\mathrm{DM}+\mathrm{Ob}-)$. Obesity was defined using World Health Organization criteria $\left(\mathrm{BMI}>=30 \mathrm{~kg} / \mathrm{m}^{2}\right)$.

Additionally, diabetic subjects were divided into two groups according to presence of abdominal obesity. We classified male participants with WC $>102 \mathrm{~cm}$ and female participants with $\mathrm{WC}>88 \mathrm{~cm}$ as subjects with abdominal obesity (AOb). Group 1 included 138 nondiabetic subjects without abdominal obesity (DM- AOb-) defined as the control group, Group 2 consisted of 67 diabetic subjects without abdominal obesity (DM- AOb-) and Group 3 contained 74 participants with diabetes and abdominal obesity $(\mathrm{DM}+\mathrm{AOb}+)$. Patients included in the study had been stabilized according to their previous medical treatment in the outpatient clinic for up to three months before entrance to the study. This study had been approved by the local scientific committee, and all participants gave informed consent before entering the study.

\section{Biochemical parameters}

Blood sampling for full chemistry and metabolic parameters, including total cholesterol, HDL and LDL cholesterol, triglycerides, fasting glucose, $\mathrm{HbA1C}$, fasting insulin, CRP and serum aldosterone and plasma renin activity, was performed. Glucose was measured using the Aeroset chemistry system (Abbott Diagnostics), high-density lipoprotein cholesterol (HDL) and triglycerides were assayed using an Aeroset automated analyzer (Abbott Diagnostics, Berkshire, UK), low-density lipoprotein cholesterol (LDL) was calculated using Friedewald's formula and insulin was measured using an immunometric assay specific for human insulin (Invitron, Monmouth, UK). Serum aldosterone and plasma renin activity were measured in a sitting position using commercially available radioimmunoassay. The lower limits of the serum aldosterone and plasma renin activity were $0.6 \mathrm{ng} / \mathrm{dl}$ and $0.1 \mathrm{ng} / \mathrm{ml} / \mathrm{h}$, respectively. The samples were measured in duplicate. Homeostasis model assessment-insulin resistance (HOMA-IR) was calculated by the following formula: fasting plasma insulin $(\mathrm{mU} / \mathrm{ml}) \times$ fasting plasma glucose $(\mathrm{mg} / \mathrm{dl}) / 405$.

\section{Blood pressure and arterial stiffness measurement}

The hemodynamic measurements were performed between 8 and $11 \mathrm{AM}$ in a quiet room at $20-23^{\circ} \mathrm{C}$ after resting for $15 \mathrm{~min}$. Blood pressure (BP) was measured using an automated digital oscillometric device (Omron model HEM 705-CP, Omron Corporation, Tokyo, Japan), and a mean of three readings was taken. Pulse wave velocity was measured by recording of the right carotid and the right radial artery pulse waveforms by two pressure transducers using the SphygmoCor Vx PWV System. The radial pressure waveform was recorded and subsequently transformed by using a validated generalized transfer function incorporated in the SphygmoCor (version 7.1, AtCor Medical, Sydney, Australia) to give an estimate of the corresponding central ascending aortic pulse wave. With the integral software, the central augmented pressure was calculated as the difference between the early and late systolic peaks of the estimated central pressure waveform. Central aortic augmentation index (AI) was calculated as the aortic augmented pressure expressed as a percentage of the pulse pressure and automatically adjusted to heart rate of 75 beats/minute. This technique, which has been validated for its reproducibility and used extensively, had been accepted as substantially equivalent to aortic pressure measured by invasive catheterization [10].

\section{Statistical analysis}

Analysis of data was carried out using SPSS 11.0 statistical analysis software (SPSS Inc., Chicago, IL, USA). For continuous variables, such as hemodynamic, arterial compliance and chemistry parameters, descriptive statistics were calculated and reported as mean \pm standard deviation. Normalcy of distribution of continuous variables was assessed using the Kolmogorov-Smirnov test (cut off at $\mathrm{p}=0.01$ ). Continuous variables were compared across groups using one-way analysis of variance (ANOVA). Variables for which across-group differences were detected underwent post hoc pairwise 
testing using the Bonferroni test. Categorical variables such as comorbidities and prescribed medications were described using frequency distributions and are presented as frequency (\%). Categorical variables were compared across groups using the chi-square test (exact as needed). Pearson's correlation analysis was used to calculate correlation coefficients to describe associations between continuous variables. Pulse wave velocity and augmentation index were modeled using multiple linear regression analysis with a backward, stepwise approach. For inclusion, the probability of $\mathrm{F}$ was set at 0.05 , and at 0.10 , for exclusion. Variables for inclusion were identified in univariate associations with the outcome of interest. All tests are two-sided and considered significant at $\mathrm{p}<0.05$.

\section{Results}

Between group comparisons by BMI

Demographic and clinical characteristics of the three groups are presented in Table 1. As expected, BMI was significantly higher in Group 3, as compared to Group 1 and Group 2; whereas, Groups 1 and 2 did not differ from one another. However, Group 1 and Group 2 differed significantly in terms of age, presence HTN, smoking and concomitant medications. As can be seen, parameters, such as total, LDL-, HDL- cholesterol, triglycerides, fasting glucose, HbA1C and HOMA-IR, differed significantly between Group 1 and Group 3. CRP levels and parameters of glucose homeostasis such as fasting glucose and HbA1C were significantly higher and HOMA-IR was marginally higher in obese diabetic subjects compared to non obese diabetics. Systolic as well as diastolic blood pressure values increased consistently from Group 1 to Group 3.

As shown in Figure 1 and Table 1, diabetic subjects with and without overall obesity did not differ from one another in terms of AI and PWV $(p=0.064)$. As expected, non obese subjects without diabetes (DM-Ob-) had significantly lower PWV as well as AI than the two diabetic groups $(\mathrm{p}<0.0001)$.

\section{Between group comparisons by WC}

As can be seen in Table 2, WC was significantly higher in Group 3, as compared to Group 2 and Group 3; whereas,

Table 1 Demographic and clinical characteristics of study groups defined by BMI

\begin{tabular}{|c|c|c|c|}
\hline \multirow[t]{2}{*}{ Variables } & \multirow{2}{*}{$\begin{array}{l}\text { Group } 1 \\
\text { DM-Ob- }\end{array}$} & \multirow{2}{*}{$\begin{array}{l}\text { Group } 2 \\
\text { DM + Ob- }\end{array}$} & \multirow{2}{*}{$\begin{array}{l}\text { Group } 3 \\
\mathrm{DM}+\mathrm{Ob}+\end{array}$} \\
\hline & & & \\
\hline Age (years) & $56.2 \pm 12.2$ & $66.7 \pm 8.4^{*}$ & $61.4 \pm 8.7$ \\
\hline BMI (kg/m2) & $24.8 \pm 2.3$ & $25.5 \pm 2.4$ & $34.2 \pm 3.7^{*}$ \\
\hline Hypertension & $10 \%$ & $64.5 \% *$ & $63.3 \%^{*}$ \\
\hline Smoker & $8.3 \%$ & $22.6 \% *$ & $15.2 \%$ \\
\hline Aspirin use & $5.6 \%$ & $53 \% *$ & $39 \% *$ \\
\hline Insulin use & $0.0 \%$ & $29 \%^{*}$ & $36.7 \% *$ \\
\hline Metformin use & $0.0 \%$ & $80.6 \% *$ & $69.6 \% *$ \\
\hline ACEI/ARB use & $16.0 \%$ & $64.5 \% *$ & $63.3 \% *$ \\
\hline CC Blocker use & $14.6 \%$ & $38.7 \% *$ & $32.9 \%$ \\
\hline Beta blocker use & $16.76 \%$ & $48.4 \%^{*}$ & $46.8 \% *$ \\
\hline Statin use & $13.2 \%$ & $69.4 \% *$ & $58.2 \% *$ \\
\hline Fasting plasma glucose(mg/dl) & $93.4 \pm 9.8$ & $147.9 \pm 43.9^{*}$ & $164.4 \pm 58.4^{*}$ \\
\hline $\mathrm{HbA} 1 \mathrm{C}(\%)$ & $5.9 \pm 0.4$ & $7.4 \pm 1.4^{*}$ & $8.1 \pm 1.7^{*}$ \\
\hline Low density lipoprotein cholesterol (mg/dl) & $119.0 \pm 31.6$ & $99.0 \pm 30.3$ & $93.8 \pm 29.3^{*}$ \\
\hline High density lipoprotein cholesterol (mg/dl) & $53.7 \pm 12.0$ & $46.3 \pm 10.4^{*}$ & $45.1 \pm 13.1^{*}$ \\
\hline Triglycerides (mg/dl) & $119.0 \pm 59.1$ & $144.3 \pm 104.8$ & $166.0 \pm 109.3^{*}$ \\
\hline C-reactive protein (mg/dl) & $0.3 \pm 0.3$ & $0.5 \pm 0.8^{*}$ & $0.9 \pm 1.3^{*}$ \\
\hline HOMA IR & $1.9 \pm 1.2$ & $6.0 \pm 13.0$ & $10.9 \pm 17.7^{*}$ \\
\hline Creatinine (mg/dl) & $0.9 \pm 1.2$ & $1.1 \pm 0.9^{*}$ & $1.0 \pm 0.5^{*}$ \\
\hline Systolic blood pressure (mmHg) & $124.7 \pm 15.6$ & $141.4 \pm 19.9^{*}$ & $154.1 \pm 20.1^{*}$ \\
\hline Diastolic blood pressure $(\mathrm{mmHg})$ & $69.3 \pm 9.0$ & $74.1 \pm 9.6^{*}$ & $78.7 \pm 9.9^{*}$ \\
\hline $\operatorname{Al}(\%)$ & $29.6 \pm 9.6$ & $36.8 \pm 8.8^{*}$ & $35.6 \pm 11.3^{*}$ \\
\hline $\mathrm{PWV}(\mathrm{m} / \mathrm{sec})$ & $6.1 \pm 1.0$ & $7.5 \pm 2.7^{*}$ & $7.5 \pm 3.2^{*}$ \\
\hline
\end{tabular}

By-group comparisons made using one way analysis of variance (ANOVA) simultaneously comparing all three groups. *p-value vs. group 1 (significant at the 0.05 level). 


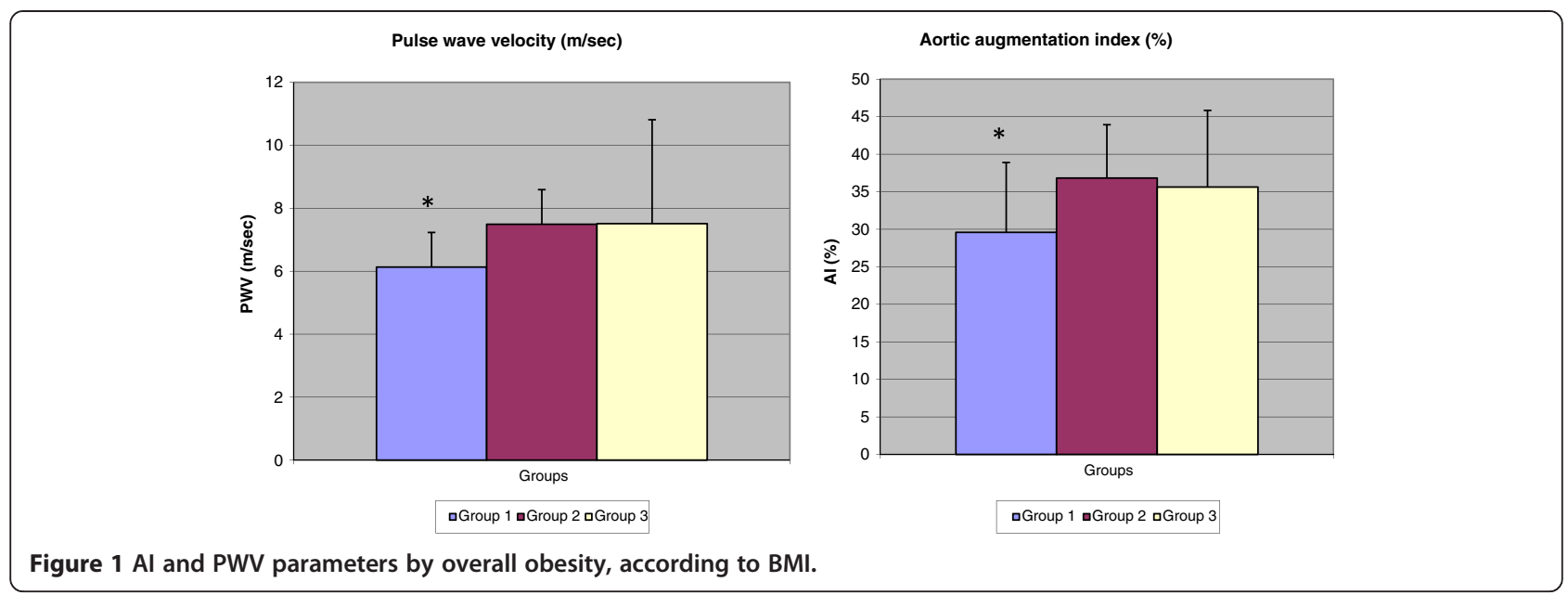

Table 2 Demographic and clinical characteristics of study groups defined by WC

\begin{tabular}{|c|c|c|c|}
\hline \multirow[t]{2}{*}{ Variables } & \multirow{2}{*}{$\begin{array}{l}\text { Group } 1 \\
\text { DM-AOb- }\end{array}$} & \multirow{2}{*}{$\begin{array}{l}\text { Group } 2 \\
\text { DM + AOb- }\end{array}$} & \multirow{2}{*}{$\begin{array}{l}\text { Group } 3 \\
\mathrm{DM}+\mathrm{AOb}+\end{array}$} \\
\hline & & & \\
\hline Age (years) & $59.2 \pm 12.4$ & $65.1 \pm 8.9^{*}$ & $62.0 \pm 8.7$ \\
\hline BMI (kg/m2) & $24.9 \pm 2.2$ & $26.8 \pm 4.1$ & $33.1 \pm 4.8^{*}$ \\
\hline Hypertension & $10.9 \%$ & $59.7 \% *$ & $67.6 \% *$ \\
\hline Smoker & $8.7 \%$ & $20.9 \%^{*}$ & $16.2 \%$ \\
\hline Aspirin use & $5.9 \%$ & $49.3 \%^{*}$ & $41.9 \% *$ \\
\hline Insulin use & $0.0 \%$ & $26.9 \%^{*}$ & $39.2 \% *$ \\
\hline Metformin use & $0.0 \%$ & $74.6 \% *$ & $74.3 \%{ }^{*}$ \\
\hline ACEI/ARB use & $16.7 \%$ & $59.7 \% *$ & $67.6 \% *$ \\
\hline CC Blocker use & $0.0 \%$ & $35.8 \% *$ & $36.8 \% *$ \\
\hline Beta blocker use & $15.2 \%$ & $44.8 \% *$ & $50 \% *$ \\
\hline Statin use & $13.8 \%$ & $64.2 \%^{*}$ & $62.2 \% *$ \\
\hline Fasting plasma glucose(mg/dl) & $93.5 \pm 9.9$ & $148.3 \pm 44.5^{*}$ & $166.0 \pm 57.6^{*}$ \\
\hline $\mathrm{HbA1C}(\%)$ & $5.9 \pm 0.4$ & $7.5 \pm 1.6^{*}$ & $8.2 \pm 1.6^{*}$ \\
\hline Low density lipoprotein cholesterol (mg/dl) & $119.8 \pm 31.1$ & $89.1 \pm 27.6^{*}$ & $94.5 \pm 31.4^{*}$ \\
\hline High density lipoprotein cholesterol (mg/dl) & $53.6 \pm 12.0$ & $46.4 \pm 11.1^{*}$ & $44.6 \pm 12.4^{*}$ \\
\hline Triglycerides (mg/dl) & $121.0 \pm 59.9$ & $156.5 \pm 108.5^{*}$ & $156.6 \pm 105.2^{*}$ \\
\hline C-reactive protein $(\mathrm{mg} / \mathrm{dl})$ & $0.3 \pm 0.3$ & $0.5 \pm 0.5$ & $0.9 \pm 1.5^{*}$ \\
\hline HOMA-IR & $2.0 \pm 1.1$ & $6.03 \pm 12.3^{*}$ & $10.8 \pm 17.8^{*}$ \\
\hline Creatinine (mg/dl) & $0.9 \pm 0.2$ & $1.0 \pm 0.4$ & $1.1 \pm 0.7^{*}$ \\
\hline Systolic blood pressure $(\mathrm{mmHg})$ & $119.2 \pm 13.9$ & $134.0 \pm 18.6^{*}$ & $153.3 \pm 20.6^{*}$ \\
\hline Diastolic blood pressure (mmHg) & $67.2 \pm 8.6$ & $73.1 \pm 9.7$ & $78.4 \pm 10.3^{*}$ \\
\hline $\mathrm{Al}(\%)$ & $29.2 \pm 9.4$ & $34.0 \pm 8.9^{*}$ & $38.8 \pm 10.4^{*}$ \\
\hline $\mathrm{PWV}(\mathrm{m} / \mathrm{sec})$ & $6.0 \pm 0.9$ & $6.9 \pm 1.8^{*}$ & $7.9 \pm 3.5^{*}$ \\
\hline
\end{tabular}

By-group comparisons made using one way analysis of variance (ANOVA).

simultaneously comparing all three groups.

${ }^{*} \mathrm{p}$-value vs. group 1 (significant at the 0.05 level). 
Groups 2 and 3 did not differ from one another. CRP level, fasting glucose, HbA1C and blood pressure increased consistently from Group 1 to Group 3.

As shown in Figure 2 and Table 2, AI as well as PWV differed significantly between groups $(\mathrm{p}<0.0001)$, such that both of them were significantly lower in non-obese non diabetic subjects than in the diabetic subjects with and without obesity. Groups 2 and 3 differed significantly from one another: AI and PWV were significantly higher in obese diabetic subjects than in the diabetic subjects without abdominal obesity $(\mathrm{p}=0.008$ and $\mathrm{p}=0.013$, respectively).

\section{General linear model of Al and PWV}

Univariate GLM analysis was carried out to control for variables, differed significantly by groups (Table 3 ). This analysis was modeled using multiple linear regression analysis with a backward, stepwise approach. For inclusion, the probability of $\mathrm{f}$ was set at 0.05 , and at 0.10 , for exclusion. Included in the model of PWV were age, sex, blood pressure, fasting glucose and BMI. Additionally, group by WC was included as a fixed factor. The model of PWV was significant $(\mathrm{p}<0.0001)$ and explained $14.5 \%$ of the variability in this outcome. Significant by-group differences in PWV persisted even after adjustment. BMI wasn't the significant independent predictor of PWV.

Additionally, general linear model of AI was carried out. The model was significant $(\mathrm{p}<0.0001)$ and explained $30.8 \%$ of the variability in this outcome. Age, sex, blood pressure, fasting glucose and BMI were included as a covariate in this model. Significant by-group differences in AI persisted even after adjustment. The model itself was significant $(\mathrm{p}<0.0001)$ and explained the variability of about $30.8 \%$ in $\mathrm{AI}$.

\section{Discussion}

In the present study, abdominal obesity defined by WC was associated with significantly higher AI and PWV in diabetic patients; whereas overall obesity defined by BMI
Table 3 Univariate GLM analysis for Al and PWV

\begin{tabular}{lll}
\hline Variables & $\begin{array}{l}\text { Al } \\
\text { Sig. }\end{array}$ & $\begin{array}{l}\text { PWV } \\
\text { Sig. }\end{array}$ \\
\hline Age & 0.000 & 0.813 \\
Sex & 0.003 & 0.007 \\
Systolic BP & 0.540 & 0.695 \\
Fasting glucose & 0.038 & 0.713 \\
BMI & 0.781 & 0.054 \\
Group* & 0.000 & 0.000
\end{tabular}

Multiple linear regression analysis was arrived at using a backward, stepwise approach with probability of $\mathrm{F}=0.05$ for entry and 0.15 for removal from the model.

*Group according to WC.

did not predict adverse vascular changes in this study population. Abdominal obesity was associated with an adverse effect on blood vessels, independently of age, sex, blood pressure, fasting glucose and BMI. Combination of diabetes mellitus and abdominal obesity, but not overall obesity, was associated with significant deterioration in terms of arterial stiffness parameters.

Findings of the present study concur with recently published data demonstrated stronger association of abdominal obesity than BMI with total mortality among elderly subjects at high risk of cardiovascular disease, particularly among diabetic participants [11]. Additionally, it was shown that the measures of abdominal obesity correlates better than BMI with arterial stiffness evaluated by PWV, and with subclinical atherosclerosis evaluated by C-IMT, in healthy, diabetics and hypertensive subjects [12].

Previous clinical and experimental data show that abdominal adipose tissue can play an important role in the development of diabetes mellitus and it can also increase the risk of cardiovascular and all-cause mortality [13,14]. Body fat distribution is one of the major determinants of metabolic health, and visceral adiposity has a stronger correlation with metabolic abnormalities and cardiovascular disease than subcutaneous adipose tissue [15-17]. Visceral fat is metabolically active and is an important
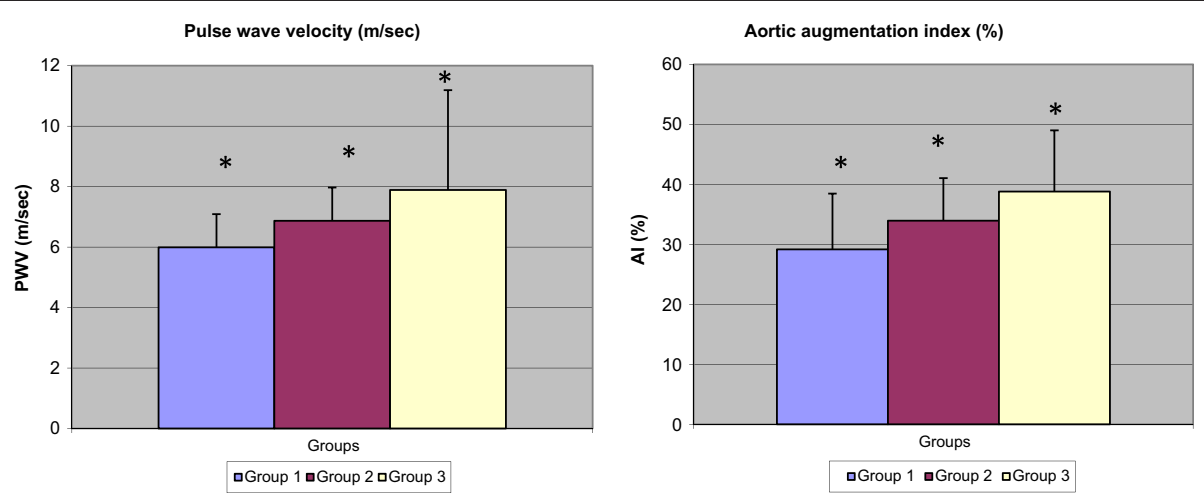

Figure $2 \mathrm{Al}$ and PWV parameters by abdominal obesity, according to WC. 
site for adipokines such as adiponectin and leptin, which plays an important role in insulin sensitivity, inflammation, lipid metabolism and atherogenesis. It was shown that low plasma adiponectin levels are significantly correlated with endothelial dysfunction, increased intima media thickness and progression of coronary artery calcification independently of other cardiovascular risk factors $[18,19]$. Leptin as well is involved in insulin sensitivity, angiogenesis, vascular and endothelial function [20]. Moreover, novel and traditional cardiovascular risk factors such as asymmetric dimethyl-arginine ADMA levels and LDLcholesterol are strongly associated with increased arterial stiffness among pre-diabetic subjects [21].

It has been demonstrated that excess body fat, abdominal visceral fat, and larger waist circumference have been associated with accelerated arterial stiffening independently of blood pressure levels, ethnicity and age in older adults [22]. Moreover, both WC and sagittal abdominal diameter (SAD) are associated with subclinical organ damage such as PWV and carotid intima-media thickness and provided information on inflammation, atherosclerosis and arterial stiffness in type 2 diabetic patients [23]. However, it has also been reported that SAD was more independent in predicting arterial stiffness over time, compared with WC, in middle-aged men and women with type 2 diabetes [24], Recently, it has been demonstrated that neck circumference is associated with an increased PWV in hypertensive adults, independent of other metabolic risk factors [25].

The pathophysiology that links abdominal adiposity to arterial stiffening is not precisely known. One suggested mechanism is through insulin resistance, which commonly accompanies obesity. A reciprocal relationship exists between insulin resistance and endothelial dysfunction, considered to be a key initiating step in the atherosclerotic cascade. Reduced insulin action in peripheral tissue impairs endothelium-dependent vasodilatation [3] and increases the local activity of a variety of growth factors in vascular tissue [26,27], promoting collagen production and the development of vascular smooth muscle cell (VSMC) hypertrophy [28]. It has been shown that obese young adults who both lower their insulin levels and lose weight showed the greatest improvement in vascular stiffness [29]. In addition, the pro-inflammatory state typical of obesity stimulates reactive oxygen species production, inhibits nitric oxide production by reducing levels of NO synthase in vascular smooth muscle cells and endothelial cells and promotes endothelial apoptosis [30,31].

In concurrence with previous studies, the present study did not detect the gender-related differences in the association between abdominal obesity measures and arterial stiffness in diabetic men and women. However, it has also been reported, that increasing BMI, WC, visceral fat area and fat mass were independently associated with higher PWV in women, but not in men, after adjustment for age, hypertension and type 2 diabetes [32].

The individuals with normal weight and increased levels of abdominal obesity could be genetically predisposed to the development of diabetes mellitus as well as CV disease. Since vascular changes inflicted by multiple environmental and genetic factors, develop years before an event, detection of vascular damage can serve as a predictor of future cardiovascular complications. In the present study, WC was a significant independent predictor of early vascular adverse changes detected by using PWV and AI. Therefore, abdominal obesity defined by WC, might be a better predictor of arterial stiffness as well as future cardiovascular events in diabetic patients.

In conclusion, the present study demonstrated that abdominal obesity, defined by WC is associated with an adverse effect on blood vessels, independently of age, sex, and blood pressure, parameters of glucose homeostasis and BMI in type 2 diabetic patients. Combination of diabetes mellitus and increased WC, but not increased BMI, was associated with significant deterioration in terms of arterial stiffness parameters in this study population. The precise mechanisms for these vascular changes, as well as overall clinical impact of WC reduction on cardiovascular outcomes deserve further investigation.

\section{Competing interests}

The authors declare that they have no competing interests.

\section{Authors' contributions}

$A L$ - practical performance, DG, MD - data analysis, preparation manuscript, critical review manuscript, MS, MD- study design, practical performance, preparation manuscript, critical review manuscript, All authors read and approved the final manuscript.

\section{Author details}

${ }^{1}$ Departments of Medicine, Wolfson Medical Center, Holon, Israel. 2Departments of Endocrinology, Wolfson Medical Center, POB 5, Holon 58100 , Israel. ${ }^{3}$ Sackler Faculty of Medicine, Tel Aviv University, Tel Aviv, Israel.

Received: 7 August 2014 Accepted: 5 October 2014

Published online: 22 October 2014

\section{References}

1. Zieman SJ, Melenovsky V, Kass DA: Mechanisms, pathophysiology, and therapy of arterial stiffness. Arterioscler Thromb Vasc Biol 2005, 25:932-943.

2. Giannattasio C, Mancia G: Arterial distensibility in humans. Modulating mechanisms, alterations in diseases and effects of treatment. $J$ Hypertens 2002, 20:1889-1899.

3. Montagnani M, Quon MJ: Insulin action in vascular endothelium: potential mechanisms linking insulin resistance with hypertension. Diabetes Obes Metab 2000, 2:285-292.

4. Greenfield GR, Samaras K, Chisholm DJ, Campbell LV: Effect of postprandial insulinemia and insulin resistance on measurement of arterial stiffness (augmentation index). Int J Cardio/ 2007, 114:50-56.

5. Suraamornkul S, Kwancharoen $R$, Ovartlarnporn $M$, Rawdaree $P$, Bajaj $M$ : Insulin clamp-derived measurements of insulin sensitivity and insulin secretion in lean and obese asian type 2 diabetic patients. Metab Syndr Relat Disord 2010, 8(2):113-118.

6. Meneilly GS, Elliott T: Metabolic alterations in middle-aged and elderly obese patients with type 2 diabetes. Diabetes Care 1999, 22:112-118. 
7. Liao J, Farmer J: Arterial stiffness as a risk factor for coronary artery disease. Curr Atheroscler Rep 2014, 16(2):387.

8. Van Popele NM, Grobbee DE, Bots ML, Asmar R, Topouchian J, Reneman RS, Hoeks AP, van der Kuip DA, Hofman A, Witteman JC: Association between arterial stiffness and atherosclerosis: the Rotterdam study. Stroke 2001, 32:454-460.

9. Cruickshank K, Riste L, Anderson SG, Wright JS, Dunn G, Gosling RG: Aortic pulse-wave velocity and its relationship to mortality in diabetes and glucose intolerance. An integrated index of vascular function?. Circulation 2002, 106:2085-2090.

10. O'Rourke M, Staessen JA: Clinical application of arterial stiffness definitions and reference values. Am J Hypertens 2002, 15:426-444.

11. Martínez-González MA, García-Arellano A, Toledo E, Bes-Rastrollo M, Bulló M, Corella D, Fito M, Ros E, Lamuela-Raventós RM, Rekondo J, Gómez-Gracia E, Fiol M, Santos-Lozano JM, Serra-Majem L, Martínez JA, Eguaras S, SáezTormo G, Pintó X, Estruch R: Obesity indexes and total mortality among elderly subjects at high cardiovascular risk: the PREDIMED study. PLoS One 2014, 29:9(7).

12. Recio-Rodriguez Jl, Gomez-Marcos MA, Patino-Alonso MC, Agudo-Conde C, Rodriguez-Sanchez E, Garcia-Ortiz L, Vasorisk group: Abdominal obesity vs general obesity for identifying arterial stiffness, subclinical atherosclerosis and wave reflection in healthy, diabetics and hypertensive. BMC Cardiovasc Disord 2012, 12:3.

13. Cox BD, Whichelow MJ, Prevost AT: The development of cardiovascular disease in relation to anthropometric indices and hypertension in British adults. Int J Obes Relat Metab Disord 1998, 22:966-973.

14. Taylor AE, Ebrahim S, Ben-Shlomo Y, Martin RM, Whincup PH, Yarnell JW, Wannamethee SG, Lawlor DA: Comparison of the associations of body mass index and measures of central adiposity and fat mass with coronary heart disease, diabetes, and all-cause mortality: a study using data from 4 UK cohorts. Am J Clin Nutr 2010, 91:547-556.

15. Fox CS, Massaro JM, Hoffmann U, Pou KM, Maurovich-Horvat P, Liu CY, Vasan RS, Murabito JM, Meigs JB, Cupples LA, D'Agostino RBS, O'Donnell CJ: Abdominal visceral and subcutaneous adipose tissue compartments: association with metabolic risk factors in the Framingham heart study. Circulation 2007, 116(1):39-48.

16. Liu J, Fox CS, Hickson DA, May WD, Hairston KG, Carr JJ, Taylor HA: Impact of abdominal visceral and subcutaneous adipose tissue on cardiometabolic risk factors: the Jackson heart study. J Clin Endocrinol Metab 2010, 95(12):5419-5426.

17. Pou KM, Massaro JM, Hoffmann U, Vasan RS, Maurovich-Horvat P, Larson MG, Keaney JF Jr, Meigs JB, Lipinska I, Kathiresan S, Murabito JM, O'Donnell CJ, Benjamin EJ, Fox CS: Visceral and subcutaneous adipose tissue volumes are cross-sectionally related to markers of inflammation and oxidative stress: the Framingham heart study. Circulation 2007, 116(11):1234-1241.

18. Tan KCB, Xu A, Chow WS, Lam MCW, Ai VHG, Tam SCF, Lam KSL: Hypoadiponectinemia is associated with impaired endotheliumdependent vasodilation. J Clin Endocrinol Metab 2004, 89:765-769.

19. Störk S, Bots ML, Angerer P, Schacky C, Grobbee DE, Angermann CE, Seufert J: Low levels of adiponectin predict worsening of arterial morphology and function. Atherosclerosis 2007, 194:e147-e153.

20. Yang R, Barouch LA: Leptin signaling and obesity: cardiovascular consequences. Circ Res 2007, 101:545-559.

21. Protopsaltis I, Foussas S, Angelidi A, Gritzapis A, Sergentanis TN, Matsagos S, Tzirogiannis K, Panoutsopoulos Gl, Dimitriadis G, Raptis S, Melidonis A: Impact of ADMA, endothelial progenitor cells and traditional cardiovascular risk factors on pulse wave velocity among prediabetic individuals. Cardiovasc Diabetol 2012, 11:141.

22. Sutton-Tyrrell K, Newman A, Simonsick EM, Havlik R, Pahor M, Lakatta E, Spurgeon $\mathrm{H}$, Vaitkevicius P: Aortic stiffness is associated with visceral adiposity in older adults enrolled in the study of health, aging, and body composition. Hypertension 2001, 38:429-433.

23. Dahlén EM, Tengblad A, Länne T, Clinchy B, Ernerudh J, Nystrom FH, Östgren CJ: Abdominal obesity and low-grade systemic inflammation as markers of subclinical organ damage in type 2 diabetes. Diabetes Metab 2014, 40(1):76-81.

24. Dahlén EM, Bjarnegård N, Länne T, Nystrom FH, Ostgren CJ: Sagittal abdominal diameter is a more independent measure compared with waist circumference to predict arterial stiffness in subjects with type 2 diabetes-a prospective observational cohort study. Cardiovasc Diabetol 2013, 12:55.
25. Liang J, Wang Y, Li H, Liu X, Qiu Q, Qi L: Neck circumference and early stage atherosclerosis: the cardiometabolic risk in Chinese (CRC) study. Cardiovasc Diabetol 2014, 13(1):107.

26. Nickenig G, Roling J, Strehlow K, Schnabel P, Bohm M: Insulin induces upregulation of vascular AT1 receptor gene expression by posttranscriptional mechanisms. Circulation 1998, 98:2453-2460.

27. Brownlee M, Cerami A, Vlassara H: Advanced glycosylation end products in tissue and the biochemical basis of diabetic complications. N Engl J Med 1988, 318:1315-1321.

28. Rizzoni D, Porteri E, Guelfi D, Muiesan ML, Valentini U, Cimino A, Girelli A, Rodella L, Bianchi R, Sleiman I, Rossei EA: Structural alterations in subcutaneous small arteries of normotensive and hypertensive patients with non-insulin-dependent diabetes mellitus. Circulation 2001, 103:1238-1244.

29. Hughes TM, Althouse AD, Niemczyk NA, Hawkins MS, Kuipers AL, SuttonTyrrell K: Effects of weight loss and insulin reduction on arterial stiffness in the SAVE trial. Cardiovasc Diabetol 2012, 11:114

30. Ikeda U, Takahashi M, Shimada K: C-reactive protein directly inhibits nitric oxid production by cytokine-stimulated vascular smooth muscle cell. J Cardiovasc Pharmacol 2003, 42:607-611.

31. Verma S, Wang CH, Li SH, Dumont AS, Fedak PW, Badiwala MV, Dhillon B, Weisel RD, Li RK, Mickle DA, Stewart DJ: Sself-fulfilling prophecy: C-reactive protein attenuates nitric oxide production and inhibits angiogenesis. Circulation 2002, 106:913-919.

32. Nordstrand N, Gjevestad E, Dinh KN, Hofsø D, Røislien J, Saltvedt E, Os I, Hjelmesæth J: The relationship between various measures of obesity and arterial stiffness in morbidly obese patients. BMC Cardiovasc Disord 2011, 11:7.

\section{doi:10.1186/s12933-014-0141-8}

Cite this article as: Lukich et al: Normal weight diabetic patients versus obese diabetics: relation of overall and abdominal adiposity to vascular health. Cardiovascular Diabetology 2014 13:141.

\section{Submit your next manuscript to BioMed Central and take full advantage of:}

- Convenient online submission

- Thorough peer review

- No space constraints or color figure charges

- Immediate publication on acceptance

- Inclusion in PubMed, CAS, Scopus and Google Scholar

- Research which is freely available for redistribution 